\title{
METHODS
}

\section{A COMPARISON OF THE EMLEN FUNNEL AND BUSSE'S FLAT CAGE FOR ORIENTATION STUDIES}

\author{
Agnieszka Ożarowska and Reuven Yosef
}

\begin{abstract}
Ożarowska A., Yosef R. 2004. A comparison of the Emlen funnel and Busse's flat cage for orientation studies. Ring 26, 1: 59-69.

The Emlen funnel cage was introduced in 1966. Since then it has been used in numerous studies on bird orientation. In 1995, Busse proposed another technique - in the form of flat, round cylindrical cage. Busse also tested nocturnal migrants in the daytime. He, and Nowakowski and Malecka (1999), proved that birds tested in daylight and at night displayed similar distributions of their preferred directions. This study also supports their findings. Zehtindijev et al. (2003) found that results in the Emlen funnel and Busse's flat cage were coherent, despite the tests were performed in different conditions (night-day) and in different years. This study is the first one that compares results of the same individuals tested in the two types of orientation cages during the day $(N=75)$ and night $(N=17)$. Results of both methods did not differ (Watson-Williams test of mean angles, Mann-Whitney $U$-test of angular dispersion) both during the day and at night. Multiheading bird behaviour is common in both types of cages and seems to be a normal feature of orientation data. The only difference was found in bird activity (i.e. number of scratches during 10 minutes of testing) that was higher for Busse's flat cage in daytime tests.
\end{abstract}

A. Ożarowska, Bird Migration Research Station, Univ. of Gdańsk, Przebendowo, PL-84-210 Choczewo, Poland, E-mail: bioat@julia.univ.gda.pl; R. Yosef, International Birding and Research Centre in Eilat, P.O. Box 774, Eilat 88000, Israel, E-mail: ryosef@eilatcity.co.il Publication appointed to the SE European Bird Migration Network papers

Key words: migration, orientation experiments, orientation cages

\section{INTRODUCTION}

The Emlen funnel cage was first introduced in 1966 (Emlen and Emlen 1966). Since then it has been used, as proposed by authors or with some modifications, in many different studies on bird orientation - development of migratory orientation, 
several cues involved in this orientation, inheritance of migratory direction (e.g. Rabøl 1979; Helbig et al. 1989; Helbig 1991, 1992a; Weindler et al. 1995; Weindler et al. 1998; Wiltschko et al. 2001), and also in studies focused on bird migration (Sandberg et al. 1988, Hilgerloh 1989). Initially, this cage (Fig. 1) consisted of a blotting paper funnel with an inkpad base - and the footprints of the experimental birds showed their directional preferences. Nowadays, funnels are lined with typewriter correction paper and scratches are analysed on a light screen. The funnel cages are covered with glass or other transparent material. In 1995, Busse proposed another type of cage (Fig. 1): a flat, round cylinder made of two wires connected by 8 vertical cross-pieces that divide the sidewall into eight identical sectors. The top is covered with netting that allows the study bird to see the sky. The sidewall is covered with transparent foil. The cage is placed in the centre of an open cylinder made of uniformly coloured, solid plastic that prevents the study bird from seeing any landmarks other than the sky. Busse also started to test night migrants in the daytime. $\mathrm{He}$, and Nowakowski and Malecka (1999), proved that birds tested in daylight and at night displayed a very similar distribution of their preferred directions. Zehtindjiev et al. (2003) analysed orientation data on the Sedge Warbler (Acrocephalus schoenobaenus) during autumn migration in the Balkan region and found that re-
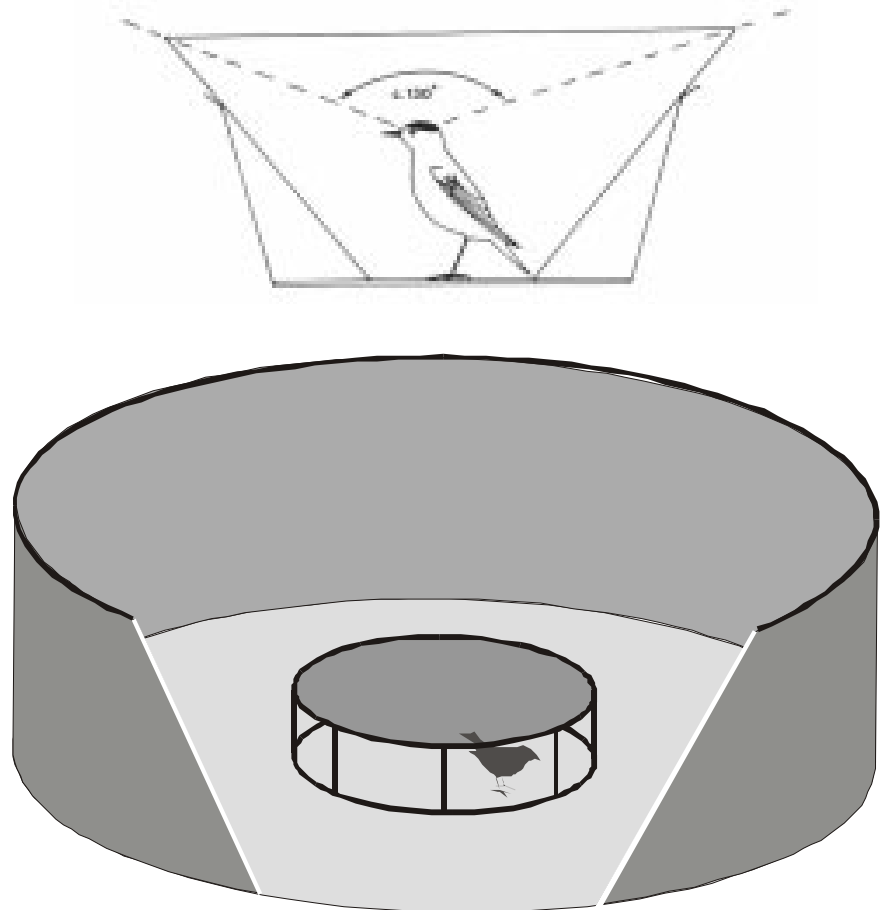

Fig. 1. Two types of orientation cages: the Emlen funnel cage (after Berthold 1996; diameter in the upper part $35 \mathrm{~cm}$, height $15 \mathrm{~cm}$ ) and the Busse's flat cage (after Busse 1995, diameter $36 \mathrm{~cm}$, height 10 $\mathrm{cm}$ - small passerines, $12 \mathrm{~cm}$ - thrushes). 
sults in the Emlen funnel and Busse's flat cage were coherent, even though the tests were performed in different conditions (night-day) and in different years. Results of the study were also in agreement with the moon-watching study of nocturnal bird migration in this region (Zehtindjiev and Liechti 2003) according to prevalence of the SW directions in autumn, however with an exception of the southeastern directions that were not common in the latter.

Nevertheless, to date no comparison has been made to check if there are any differences in data obtained from the two experimental devices, under day and night conditions, using the same individuals. We undertook this study to understand if the two experimental techniques could be interchangeable; and whether there was a difference in the preferences shown by the birds when placed in the different cages in the daytime and at night.

\section{METHODS}

\section{Data collection}

Tests were conducted at the International Birding and Research Center in Eilat (IBRCE) ringing station on several species of nocturnal migrants (Table 1) on their autumn migration in 2002. Eilat is located at the northern tip of the Gulf of Aqaba (northern tip of the eastern arm of the Red Sea), at the edge of almost $2500 \mathrm{~km}$ of continuous desert regions of the Sahel, Sahara and Sinai deserts. Hence, thousands of birds migrating from the Palearctics pass through the region, and stage at Eilat, both during autumn and spring migrations (Yom-Tov 1984, Morgan and Shirihai 1997, Yosef 1997).

Table 1

Number of tests used for the analysis; data analysed $(N)$ when distributions in both cages significantly different from random $\left(\chi^{2}\right.$-test, $\left.p<0.01\right)$

\begin{tabular}{|l|c|c|c|c|}
\hline \multirow{2}{*}{} & \multicolumn{2}{|c|}{ Day } & \multicolumn{2}{c|}{ Night } \\
\cline { 2 - 5 } & $N_{d}$ & $n s$ & $N_{n}$ & $n s$ \\
\hline Luscinia svecica & 25 & 2 & 8 & 2 \\
\hline Sylvia atricapilla & 24 & 0 & 1 & 0 \\
\hline Phoenicurus phoenicurus & 17 & 1 & 5 & 0 \\
\hline Sylvia curruca & 8 & 1 & 2 & 1 \\
\hline Sylvia melanocephala & 1 & 0 & 1 & 1 \\
\hline Total & $\mathbf{7 5}$ & $\mathbf{4}$ & $\mathbf{1 7}$ & $\mathbf{4}$ \\
\hline
\end{tabular}

Birds were caught in Heligoland traps, ringed, measured and each individual was tested in both types of orientation cages for 10 minutes in each. To randomise 
results, the cage used as the first one, was used as the second for the next tested individual. Tests were conducted both in the daytime and at night. We assume that weather conditions did not affect results as all experiments were conducted under clear skies. The results of bird activity, i.e. scratches and holes made either with claws or beak were counted with a $45^{\circ}$ precision (8 sectors).

\section{Data analysis}

Results of all tests were elaborated in the same manner. First, they were computerised with program ORIENTIN (available from the Bird Migration Research Station, University of Gdańsk, Poland). The program facilitates the preparation of all data into a standard form that can then be used by different spreadsheet programs. We used Quattro Pro 8.0 for Windows that allowed making radar (circular) graphs. Tests with less than 20 markings per experiment were excluded from the data set. Initially, all data were checked with $\chi^{2}$-test and all non-significant distributions (random distribution of the signs) were also excluded from further analysis (Table 1). The Rayleigh test, used to testing of data distribution, was not applied as it requires unimodality (Zar 1996). For each individual the distribution of its headings was elaborated according to the procedures given and discussed by Busse and Trocińska (1999). Data for all individuals (regardless of their species) tested in one type of cage were collated and summed up and these data were used to drawing radar graphs for distributions of headings in a given type of cage. As discussed by Zehtindjiev et al. (2003) these graphs show the overall patterns of tested birds' directional preferences that are quite complicated, hence, in order to discuss the differences and/or similarities of distributions we present simplified pictures. The final data were summed up in 16 sectors as suggested by Busse (pers. comm.), instead of 8 that seemed to be too general, and then calculated in percents.

The mean angles for each group, i.e. for all birds tested in one type of cage during day or night, were calculated according to circular statistics (Batschelet 1981). The Watson-Williams test was used to assess whether birds oriented differently in two types of cages or in day- and night-time tests (Zar 1996). In addition, the twotailed Mann-Whitney $U$-test was applied to compare average deviations from the mean angle (i.e. scatter) in both types of experimental cages (Zar 1996). Average bird activity (i.e. number of scratches, pecks or holes during 10 minutes of testing) in each cage was compared with the two-tailed, paired $t$-test.

\section{Results}

Figure 2 shows an overall pattern of headings distribution in the Emlen and Busse's cages in day- and night-time tests. Figure 3 presents simplified (16 sectors) data distribution in each of the orientation cages. No statistical differences were found for the results obtained in both types of cages either during day or night experiments (Table 2), both in their distribution and sample scatter. However, some dominance of SW directions (Fig. 2 and 3, Table 3), which comprise $62 \%$ of all 
Day $\quad$ Emlen funnel cage
$N_{d}=75$

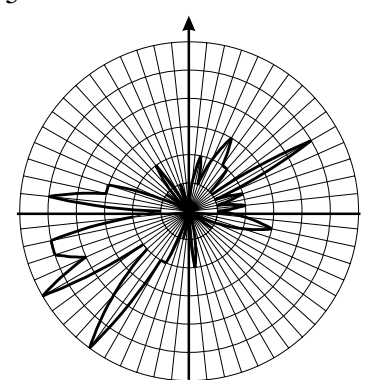

Night

$N_{n}=17$

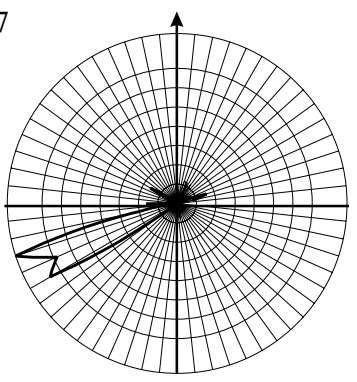

Busse's cage
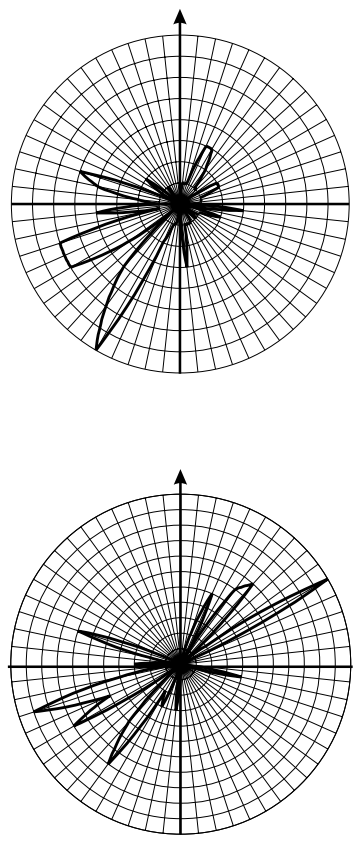

Fig. 2. An overall pattern of headings distribution in the Emlen and Busse's cages in day- and night-time experiments
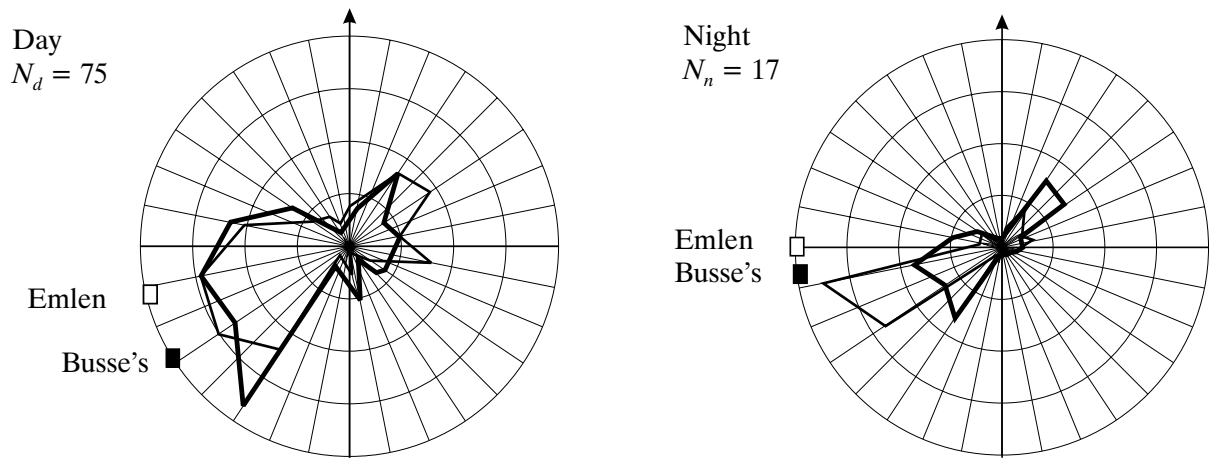

Fig. 3. Comparison of simplified (16 sectors) data distributions in each type of the orientation cage in day and night experiments. Emlen cage - thin line, Busse's cage - thick line. Rectangles point at locations of average azimuths calculated according to classic circular statistics routine.

headings, and low percentage (24\%) of NE directions for the night tests in the Emlen funnel ( $c f .49 \%$ and $33 \%$ in Busse's cage, respectively) can be noticed. It is worth to stress that average azimuths calculated according to classic circular statistics routine, and presented in Figure 3 and 4, are "virtual" azimuths for standard statistical comparison and they do not point at real migration direction as shown in cages (cf. Busse and Trocińska 1999). 
Table 2

Data analysis results ( $\alpha$ - mean angle, $r$ - mean vector length, $s$ - mean angular deviation; $n s$ - difference not significant: $p>0.05$ )

\begin{tabular}{|c|c|c|c|c|}
\hline & Emlen funnel cage & Busse's flat cage & $\begin{array}{c}\text { Watson-Williams } \\
\text { test }\end{array}$ & $\begin{array}{c}\text { Mann-Whitney } \\
U \text {-test }\end{array}$ \\
\hline Day & $\alpha=257^{\circ}$ & $\alpha=237^{\circ}$ & $n s$ \\
$N_{d}=75$ & $r=0.20$ & $r=0.34$ & $n s$ & $n$ \\
Night & $s=72.5^{\circ}$ & $s=66^{\circ}$ & $n$ \\
$N_{n}=17$ & $\alpha=271^{\circ}$ & $\alpha=266^{\circ}$ & $n s$ \\
& $r=0.49$ & $r=0.22$ & $n$ \\
\hline
\end{tabular}

Table 3

Simplified headings distribution given as percentage of NE, SE, SW and NW directions

\begin{tabular}{|c|c|c|c|c|}
\hline \multirow{2}{*}{ Day } & \multicolumn{2}{|c|}{ Emlen funnel cage } & \multicolumn{2}{c|}{ Busse's flat cage } \\
\hline \multirow{3}{*}{ Night } & $19 \% \mathrm{NW}$ & $25 \% \mathrm{NE}$ & $18 \% \mathrm{NW}$ & $20 \% \mathrm{NE}$ \\
\cline { 2 - 5 } & $42 \% \mathrm{SW}$ & $15 \% \mathrm{SE}$ & $47 \% \mathrm{SW}$ & $15 \% \mathrm{SE}$ \\
\cline { 2 - 5 } & $8 \% \mathrm{NW}$ & $24 \% \mathrm{NE}$ & $14 \% \mathrm{NW}$ & $33 \% \mathrm{NE}$ \\
\hline \multirow{2}{*}{} & $62 \% \mathrm{SW}$ & $5 \% \mathrm{SE}$ & $49 \% \mathrm{SW}$ & $5 \% \mathrm{SE}$ \\
\hline
\end{tabular}
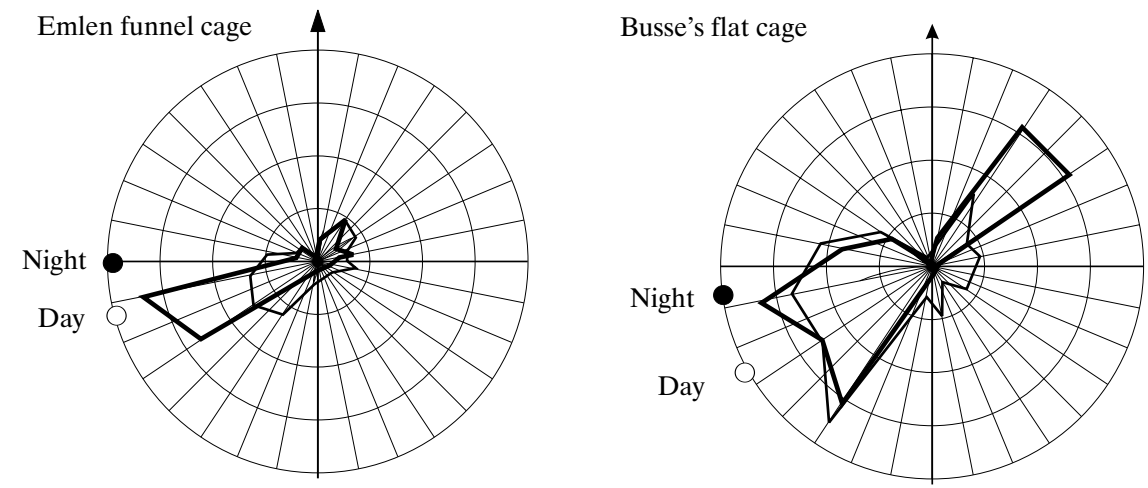

Fig. 4. Comparison of simplified (16 sectors) data distributions of day and night tests in each type of the orientation cage. Night - thick line, day - thin line. Dots point at locations of average azimuths calculated according to classic circular statistics routine.

The only difference was found in bird activity. During the day birds were more active in Busse's flat cage, while at night in Emlen funnel ( $t$-test, $p<0.001$; Table 4).

We compared results of day- versus night-time tests in each cage (Fig. 4, Table 5) as well. This analysis was not based on the same group of birds, i.e. different individuals were tested in the daytime and at night, also the number of day tests was much higher. Nevertheless, no differences in the distributions were found (the sample scatters were not compared due to large differences in test numbers). 
Table 4

Average bird activity (i.e. number of scratches, etc.

during 10 minutes of testing) in both types of cages

\begin{tabular}{|c|c|c|}
\hline & Emlen funnel cage & Busse's flat cage \\
\hline Day & 141 & 193 \\
\hline Night & 100 & 73 \\
\hline
\end{tabular}

Table 5

Data analysis results ( $\alpha$ - mean angle, $r$ - mean vector length, $s-$ mean angular deviation; $n s$ - difference not significant: $p>0.05)$.

\begin{tabular}{|c|c|c|c|}
\hline & Day & Night & Watson-Williams test \\
& $N_{d}=75$ & $N_{n}=17$ & \\
\hline \multirow{3}{*}{ Emlen funnel cage } & $\alpha=257^{\circ}$ & $\alpha=271^{\circ}$ & $\boldsymbol{n} \boldsymbol{}$ \\
& $r=0.20$ & $r=0.49$ & \\
& $s=72.5^{\circ}$ & $\alpha=58^{\circ}$ & $\boldsymbol{n} \mathbf{s}$ \\
\hline \multirow{3}{*}{ Busse's flat cage } & $\alpha=237^{\circ}$ & $r=0.22$ & \\
& $r=0.34$ & $s=71.5^{\circ}$ & \\
& $s=66^{\circ}$ & & \\
\hline
\end{tabular}

Data were also analysed with regard to the percentage of individuals that showed uni- or multi-heading behaviour, i.e. whether one or several vectors for an individual were found. In both types of cages the numbers were similar, with a dominance of two-vector birds; nevertheless, it has to be noted that in daytime tests this prevalence is a little bit larger for the Emlen funnel cage (Table 6).

Table 6

Percentage of individuals showing uni- or multi-heading behaviour in both cages

\begin{tabular}{|l|c|c|c|c|}
\hline \multirow{2}{*}{$\begin{array}{c}\text { Number of vectors shown } \\
\text { by an individual }\end{array}$} & \multicolumn{2}{|c|}{ Day } & \multicolumn{2}{c|}{ Night } \\
\cline { 2 - 5 } & $\begin{array}{c}\text { Emlen funnel } \\
\text { cage }\end{array}$ & Busse's flat cage & $\begin{array}{c}\text { Emlen funnel } \\
\text { cage }\end{array}$ & Busse's flat cage \\
\hline One vector & 9 & 17 & 6 & 6 \\
\hline Two vectors & 60 & 48 & 76 & 76 \\
\hline Three vectors & 31 & 31 & 18 & 18 \\
\hline Four vectors & 0 & 4 & 0 & 0 \\
\hline
\end{tabular}

\section{DISCUSSION}

Since the Emlen funnel cage was first introduced in 1966 (Emlen and Emlen 1966), it has been used in different studies on bird orientation and to a very limited extent in order to understand migration. It is a pity, as cage tests/experiments could be a very useful, complementary method to ringing data analysis in studies on bird 
migration. Helbig (1992b) found that ringing results (recovery data) and orientation tests (Emlen funnel cage) on hand-raised migrants concurred well and stated that cage orientation during migration season accurately reflected natural directional preferences. Comparison with other methods of investigating bird migration - e.g. radar (Nievergelt et al. 1999), moon-watching (Zehtindjiev et al. 2003) showed that there was a general agreement of flight directions and directional preferences found in orientation cages. Zehtindjiev et al. (2003) analysed orientation data on the Sedge Warbler and, amongst others, they also compared results of two different experimental methods and procedures - Emlen funnel and night tests versus Busse's cage and daytime tests - but the tests were performed in different conditions and years (Emlen funnel cage: autumn 2001, night-time tests; Busse's flat cage: autumn 2002, daytime tests). Even so, they found the results coherent. In this study, we compared results of tests performed on exactly the same group of birds and, despite the differences both in cage construction and some novelty in test/experiment routine (e.g. daytime experiments on nocturnal migrants), the results of day and night tests in two types of cages, i.e. Emlen funnel and Busse's flat cage are similar. Some decrease in percentage of NE directions, which we can define as "reverse" directions (because all distribution mean angles found in this study were SW, and analysis is based on autumn migration data), reported for the night tests in Emlen funnel cage seems not to be a common feature as Zehtindjiev et al. (2003) found these reverse directions in both types of cages.

As no difference in the preferred directions between day and night tests was found, this analysis supports previous findings by Busse (1995), Nowakowski and Malecka (1999) that orientation tests on nocturnal migrants can be performed also during daytime. Our results suggest that both methods are equally reliable and can be interchangeable in studies on bird migration.

In our study, multi-heading bird behaviour was common in both types of cages, and it appears that such behaviour seems to be normal feature of orientation data and has to be taken into account when calculation procedures are applied - for more detailed discussion see Busse and Trocińska (1999).

Since the results of both cages are similar, we focused on some methodical aspects, concerning cage construction and work routine.

\section{Cage construction}

Nievergelt and Liechti (2000) discussed some methodical aspects of investigating migratory activity in Emlen funnels. They investigated methodical biases to the cage construction and it appeared that birds were slightly attracted by the joint of the Tipp-Ex ${ }^{\circledR}$ paper. Small songbirds, like Reed Warbler (A. scirpaceus) or Willow Warbler (Phylloscopus trochilus), produced almost exclusively weak scratches that could only be detected in appropriate light conditions, therefore would often be classified as inactive, if only the clearly visible scratches were counted. Moreover, they discussed environmental condition, i.e. influence of atmospheric humidity, and 
found that in dry air conditions the bird's activity is underestimated, as the typewriter correcting paper was more likely to be scratched off when humidity was high. In these aspects, the Busse's flat cage has some advantage over the Emlen funnel in that scratches left by small birds like the Willow Warbler, though sometimes difficult to count, are clearly visible. Atmospheric humidity also has some influence on the Busse's cage, i.e. birds cannot be tested in rain/snow or fog.

Although we found no difference in scatter, one has to note that the mean angular deviations in the night were slightly different. Maybe this is because the flat cage leaves too much open space for the bird enabling it to move easily in any direction it wants.

Difference in cage construction could be also a reason for different bird activity; this difference is even higher if one takes into account that in the Emlen funnel each scratch is counted separately, so one jump of a bird means about 6 scratches (Beck and Wiltschko 1983), while in the Busse's cage more often these are holes made with a beak - one move means only one hole. So in fact the difference observed in night experiments can be misleading.

\section{Work routine}

Cage experiments met some criticism (e.g. Gerrard 1981) mainly because birds are stressed by unusual situation and would like simply to escape rather than "migrate". As the reaction to these objections birds were caged some time before experiments in order to acclimatise individuals with a cage. In our opinion, this way even birds caught on migration were disturbed. Testing birds in the daytime enables us to study bird migratory behaviour that is not distorted because of the needs of experiment. In this aspect Busse's method has great advantages over other methods.

Also simple counting of final test results is much quicker in Busse's method enabling to process up to 6 birds in an hour at one experiment stand (well-trained person is able to work at two stands simultaneously), thus giving a large sample size in a relatively short time.

\section{CONCLUSIONS}

1. The results (of both day and night tests) for Emlen funnel and Busse's flat cage are:

- similar

- in distribution and scatter,

- in multi-heading bird behaviour, which is common in both types of cages, and seems to be a normal feature of orientation data,

- different in bird activity

These suggest that both methods are equally reliable and can be interchaneable in studies on bird migration.

2. Orientation tests on nocturnal migrants can be performed during daytime. 


\section{ACKNOWLEDGEMENTS}

We are grateful to the volunteers of the International Birding and Research Center in Eilat that worked hard throughout the season to test as many birds as possible, thus giving us the basis for this study.

\section{REFERENCES}

Batschelet E. 1981. Circular statistics in biology. Academic Press, London.

Berthold P. 1996. Control of bird migration. Chapman and Hall. London

Beck W., Wiltschko W. 1983. Orientation behaviour recorded in registration cages: a comparison of funnel cages and radial perch cages. Behaviour 87: 145-156.

Busse P. 1995. New technique of a field study of directional preferences of night passerine migrants. Ring 17 , 1-2: 97-116.

Busse P., Trocińska A. 1999. Evaluation of orientation experiment data using circular statistics - doubts and pitfalls in assumptions. Ring 21, 2: 107-130.

Emlen S.T., Emlen J.T.Jr. 1966. A Technique for Recording Migratory Orientation of Captive Birds. Auk 83: 361-367.

Gerrard E.C. 1981. Instinctive navigation of birds. Broadford.

Helbig J.A. 1991. Inheritance of migratory direction in a bird species: a cross-breeding experiment with SEand SW-migrating blackcaps (Sylvia atricapilla). Behav. Ecol. Sociobiol. 28: 9-12.

Helbig J.A. 1992a. Ontogenetic stability of inherited migratory directions in a nocturnal bird migrant: comparison between the first and second year of life. Ethology, Ecology \& Evolution 4: 375-388.

Helbig J.A. 1992b. Population differentiation of migratory directions in birds: comparison between ringing results and orientation behaviour of hand-raised migrants. Oecologia 90: 483-488.

Helbig J.A., Berthold P., Wiltschko W. 1989. Migratory Orientation of Blackcaps (Sylvia atricapilla): Population-specific Shifts of Direction during the Autumn. Ethology 82: 307-315.

Hilgerloh G. 1989. Orientation of Trans-Saharan Passerine Migrants in Southwestern Spain. Auk 106: 501-502.

Morgan J.H., Shirihai H. 1997. Passerines and Passerine Migration in Eilat. IBCE Tech. Publ. 6, 1: 50 pp.

Nievergelt F., Liechti F. 2000. Methodische Aspekte zur Untersuchung der Zugaktivität im Emlen-Trichter. J. Ornithol. 141: 180-190.

Nievergelt F., Liechti F., Bruderer B. 1999. Migratory directions of free-flying birds versus orientation in registration cages. J. Exp. Biol. 202: 2225-2231.

Nowakowski J.K., Malecka A. 1999. Test of Busse's method of studying directional preferences of migrating small Passeriformes. Acta orn. 34: 37-44.

Rabøl J. 1979. Magnetic orientation in night-migrating passerines. Ornis Scand. 10: 69-75.

Sandberg R., Pettersson J., Alerstam T. 1988. Why do migrating robins, Erithacus rubecula, captured at two nearby stop-over sites orient differently? Anim. Behav. 36: 865-876.

Weindler P., Beck W., Liepa V., Wiltschko W. 1995. Development of migratory orientation in pied flycatchers in different magnetic inclinations. Anim. Behav. 49: 227-234.

Weindler P., Liepa V., Wiltschko W. 1998. The Direction of Celestial Rotation Affects the Development of Migratory Orientation in Pied Flycatchers, Ficedula hypoleuca. Ethology 104: 905-915.

Wiltschko R., Munro U., Ford H., Wiltschko W. 2001. Orientation in migratory birds: time-associated relearning of celestial cues. Anim. Behav. 62: 245-250.

Yom-Tov Y. 1984. On the difference between the spring and autumn migrations in Eilat, southern Israel. Ring. \& Migr. 5: 141-144.

Yosef R. 1997. Clues to Migratory Routes of the Eastern Flyway of the Western Palearctics - Ringing Recoveries at Eilat, Israel (I - Ciconiiformes, Charadriiformes, Coraciiformes, and Passeriformes). Vogelwarte 39: 131-140. 
Zar J.H. 1996. Biostatistical Analysis. Prentice Hall, London.

Zehtindijev P., Ilieva M., Ożarowska A., Busse P. 2003. Directional behaviour of the Sedge Warbler (Acrocephalus schoenobaenus) studied in two types of orientation cages during autumn migration - a case study. Ring 25, 1-2: 53-63.

Zehtindjiev P., Liechti F. 2003. A quantitative estimate of the spatial and temporal distribution of nocturnal bird migration in south-eastern Europe - a coordinated moon-watching study. Avian Sci. 3, 1: 37-45. 